\title{
El abuso sexual infantil: análisis de un registro institucional en Quito
}

\section{Patricia Chiguano*}

La presente investigación estudia la población atendida en una institución que presta servicios en el norte del distrito Metropolitano de Quito, y que viene atendiendo casos de maltrato y abuso sexual desde el 2001. La información se basa en recopilación de datos estadísticos a partir de algunas variables e indicadores que ayuden a construir el perfil social de la casuística. La información se centró en casos de niños, niñas y adolescentes atendidos por situaciones de abuso sexual, con la finalidad de elaborar un perfil social. La investigación aborda el abuso sexual como un factor relacional en el contexto familiar: persona agredida, la agresora, la familia y el contexto del abuso sexual, respecto a la edad se considera la definida por el Código de la Niñez y Adolescencia.

Más que una selección de casos más bien se revisaron los atendidos en esta institución desde el 2001 hasta noviembre de 2004. Es importante indicar que al momento de recoger la información se agregaron algunos ítems, no contemplados desde el inició. Además, hay que destacar la poca información encontrada referente a la persona agresora. En forma general en casi todos los ítems investigados, como se podrá observar más adelante, se incluyó la categoría 'sin información', muy importante para destacar el ambiente de silencio y secreto que rodean el fenómeno del abuso sexual infantil.

Las categorías investigadas fueron cuatro:

1. La persona agredida o abusada, es la persona abusada, que ha sufrido algún tipo de abuso, desde una posición de poder o autoridad.

Se consideraron 12 subcategorías e indicadores que permiten establecer un perfil sociocultural de la persona agredida:

2. La persona agresora o abusadora, es la que ha perpetuado el acto abusivo, estadísticamente refieren que son hombres adultos, cercanos a la persona abusada, quienes generalmente abusan. Se establecieron 17 subcategorías e indicadores, cada variable se estableció en relación a cada niño, niña o adolescente.

Licenciada en Trabajo Social por la Universidad Central del Ecuador. Maestría en Políticas de Infancia, Adolescencia, Universidad Politécnica Salesiana. Coordinadora del Programa del INFA (Instituto Nacional de la Familia). 
3. Organización y estructura familiar, que abarca el contexto familiar en relación al abuso. Se determinaron cuatro subcategorías e indicadores con lo que se pretende estudiar el contexto familiar, su influencia en mantenimiento del secreto o el desvelamiento del abuso sexual; además se pretende entender que factores intervienen para producir o propiciar estos hechos en la familia.

Clase social: Es preciso aclarar que los ítems se tomaron de las contempladas en las fichas de la institución en donde se recogió la información, no se conocen los criterios utilizados para determinarlos así.

4. Contexto del abuso sexual, al hablar del contexto del abuso, no se trata de tipificar el abuso, sino de distinguir cómo se presenta el abuso sexual en los niños, niñas y adolescentes y los factores de riesgo. Se establecieron ocho subcategorías e indicadores: 1 . Tipo de contacto: con contacto y sin contacto. 2. Descripción del abuso. 3. Lesiones físicas producidas por el abuso. 4. Factores que impiden el desvelamiento. 5. Frecuencia. 6. Duración de abuso.7. Lugar de abuso. 8. Contexto de abuso desde la intervención.

\section{La investigación: resultados}

La investigación revisó 770 casos reportados por maltrato y abuso sexual, desde enero de 2001 hasta noviembre de 2004, de los cuales 73 casos fueron reportados como abuso sexual, es decir que la institución en 4 años, de la población total atendida el 9,48\% corresponde a abuso sexual infantil. Sin embargo para el estudio se tomó 49 casos de los 73 reportados, considerando que en algunos casos no existía la información necesaria, descartando estos casos, por no tener información para la investigación propuesta.

\section{Agredida-o/abusada-o}

De los 49 casos investigados se recogió información de 62 niñas, niñas y adolescentes, porque al revisar la información se identificó casos en los que constaba 2 ó más niños abusados.

Edad. La información es en años cumplidos. 


\section{Gráfico 1}

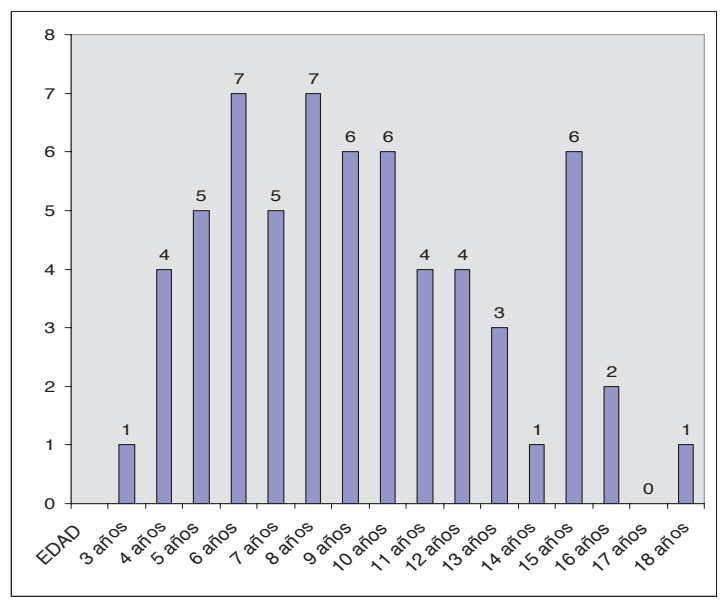

\section{Sexo}

Femenino 49

Masculino 13

\section{Instrucción}

Gráfico 2

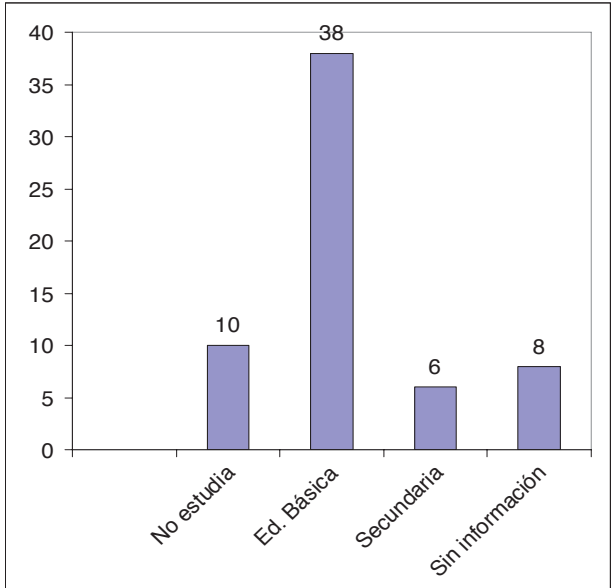




\section{Ocupación:}

Sí 5

No 47

Sin Información 10

Problemas escolares

Sí 19

No 23

Sin Información 20

Problemas de comportamiento sexual con otros niños o niñas

Sí 10

No 22

Sin Información 31

Tendencias a escapar de la casa

Sí 11

No 28

Sin Información 24

\section{Conductas delictivas}

Sí 0

No 26

Sin Información 36

\section{Conductas agresivas}

Sí 17

No 19

Sin Información 26

\section{Embarazos}

Sí 2

No 58

Sin Información 2 


\section{Discapacidad}

Sí 2

No 55

Sin Información 5

\section{Enfermedades}

Sí 10

No 32

Sin Información 20

Número de agresores por cada niña, niño o adolescente abusado Gráfico 3



\section{Relación con la/el agredido}

Padre 21, Madre 0, Padrastro 12, Hermano 4, Primo 6, Tío 7, otro familiar 1, Vecino 5, Compañero 5, Desconocido 14, otro 1, Sin Información 2. 


\section{Gráfico 4}

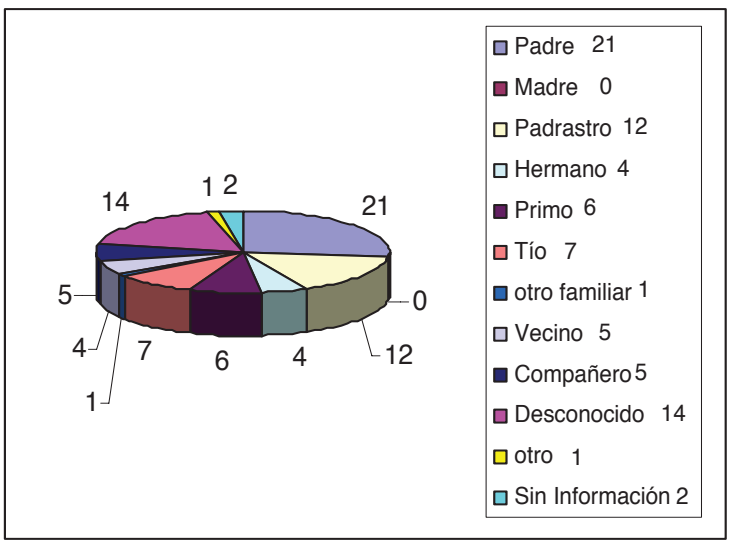

\section{La persona agresora o abusadora:}

La población investigada en esta variable, se encuentra con relación al número de agresores, tomando en cuenta que hay NNA que fueron abusados por más de 2 agresores; es decir, que son en total 77 agresores, 2 NNA reportan sin información. En términos generales en la mayoría de los ítems de esta categoría se cuenta con poca o ninguna información.

Edad. El gráfico agrupa las edades en los siguientes rangos:

Gráfico 5

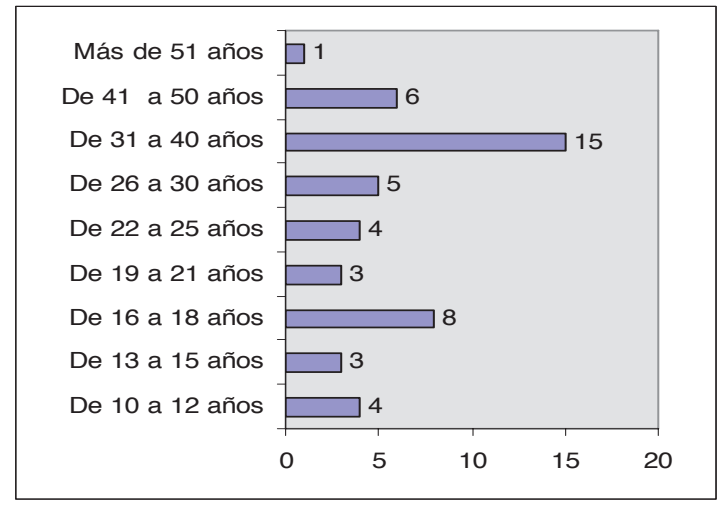




\section{Sexo}

Femenino 0

Masculino 56

Sin Información 21

\section{Instrucción}

Gráfico 6

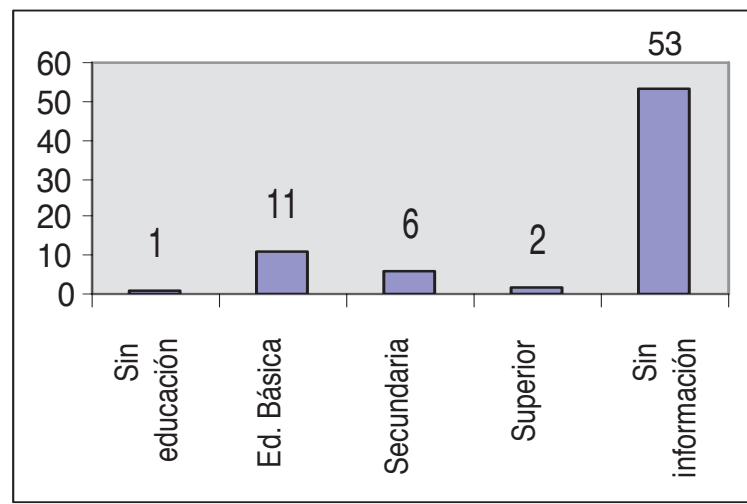

\section{Estado civil}

Gráfico 7

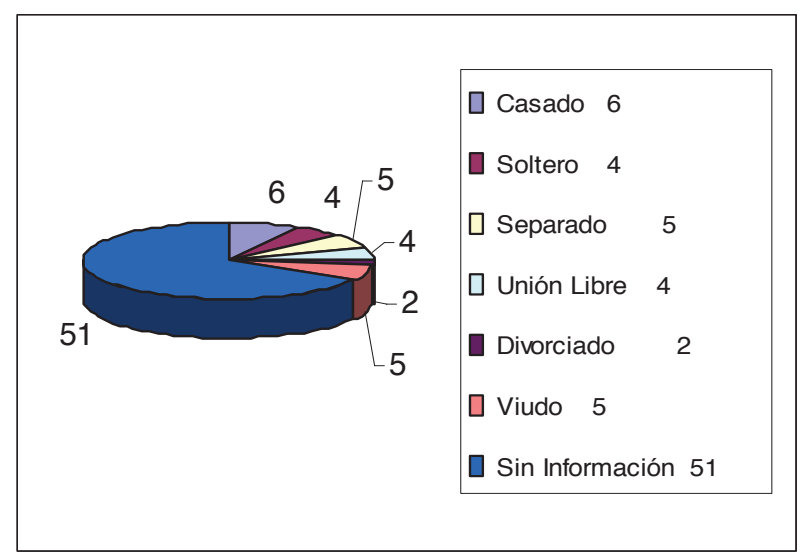




\section{Ocupación}

Sí 11

No 18

Sin Información 46

\section{Problemas psiquiátricos}

No existe información sobre este ítem.

\section{Discapacidad}

Sí 3

No 2

Sin Información 70

\section{Enfermedad}

Sí 6

No 1

Sin Información 68

\section{Problemas de alcohol}

Sí 13

No 0

Sin Información 62

Problemas de drogas

Sí 3

No 0

Sin Información 73

\section{Historia de abuso}

Sí 5

No 0

Sin Información 70 


\section{Reincidencia en abuso sexual}

Se presenta un solo caso de un abusador que es reincidente en abuso sexual.

Existe una sola persona que reporta haber sido denunciado anteriormente por abuso sexual, del resto no existe información. En un solo caso se reporta que el agresor fue penalizado por delito sexual.

\section{Antecedentes delincuenciales}

Dos personas reportadas con antecedentes delincuenciales.

\section{Estructura y organización familiar}

El total de familias estudiadas son 49 , de las cuales se obtiene la siguiente información.

\section{Organización familiar}

Gráfico 8

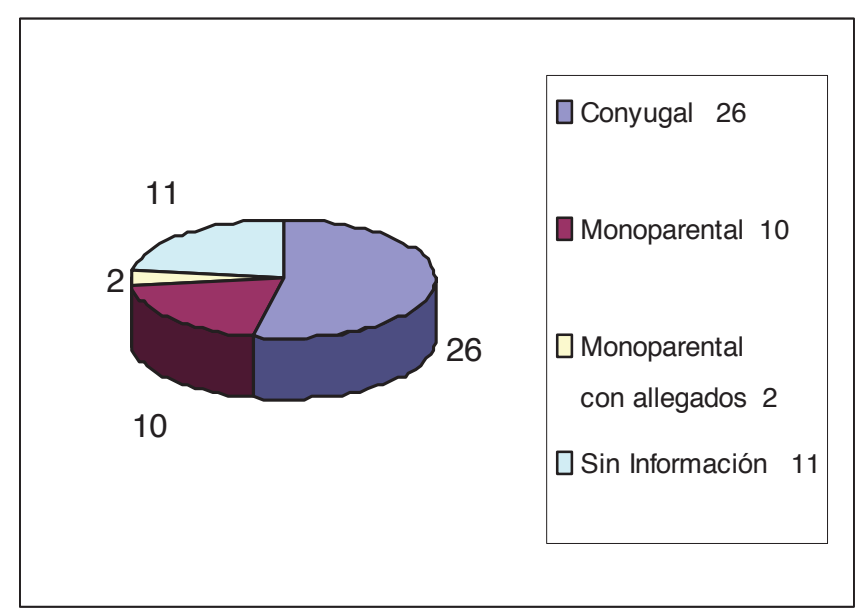




\section{Jefatura familiar}

\section{Gráfico 9}

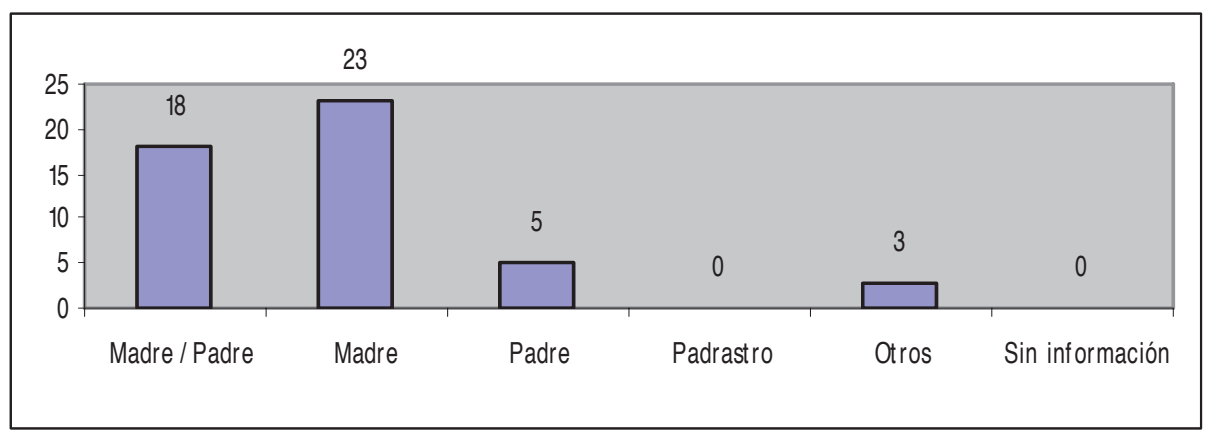

Número de hijos

Gráfico 10

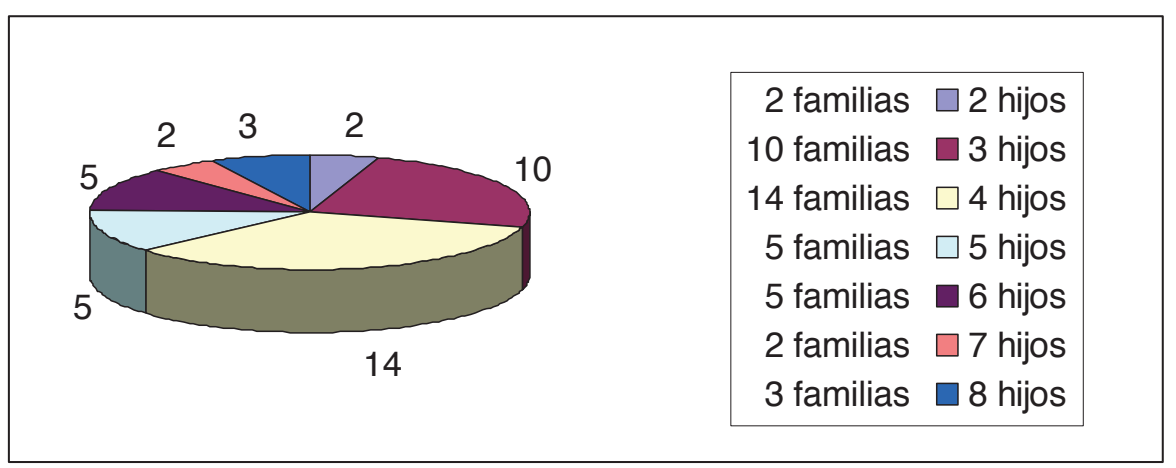

\section{Estado civil de los padres}

Casado: 5

Soltero: 13

Unión libre: 0

Divorciado: 0

Viudo: 1

Sin información: 30 
Edad de los padres o representantes

Tabla 1

\begin{tabular}{|c|c|c|c|c|c|}
\hline No. Flias & Padre & Madre & Padrastro & Otro & Sin información \\
\hline 1 & 61 & & & & 12 familias \\
\hline 2 & & 30 & 40 & & \\
\hline 3 & & 30 & 30 & & \\
\hline 4 & 37 & & & 17 & \\
\hline 5 & 31 & & 32 & & \\
\hline 6 & 28 & & 35 & & \\
\hline 7 & 29 & & 29 & & \\
\hline 8 & 40 & 44 & & & \\
\hline 9 & & 47 & & & \\
\hline 10 & & 39 & & & \\
\hline 11 & & 40 & & & \\
\hline 12 & & 52 & & & \\
\hline 13 & & 48 & & & \\
\hline 14 & 26 & 24 & & & \\
\hline 15 & 37 & 43 & & & \\
\hline 16 & 44 & 45 & & & \\
\hline 17 & 39 & 35 & & & \\
\hline 18 & 34 & 35 & & & \\
\hline 19 & 44 & 51 & & & \\
\hline 20 & 30 & 28 & & & \\
\hline 21 & 28 & 25 & & & \\
\hline 22 & & 51 & & & \\
\hline 23 & & 28 & 34 & & \\
\hline 24 & 31 & 30 & & & \\
\hline 25 & 33 & 25 & & & \\
\hline 26 & & 31 & 40 & & \\
\hline 27 & & 28 & 22 & & \\
\hline 28 & & 50 & & & \\
\hline 29 & & 33 & 35 & & \\
\hline 30 & 43 & 41 & & & \\
\hline 31 & 37 & 39 & & & \\
\hline 32 & 30 & 28 & & & \\
\hline 33 & & 42 & & & \\
\hline 34 & & 29 & & & \\
\hline 35 & & 41 & 63 & & \\
\hline 36 & 30 & 35 & & & \\
\hline 37 & & 23 & 43 & & \\
\hline
\end{tabular}

\section{Instrucción de los padres o representantes}

Se obtiene información de 9 familias: 
Tabla 2

\begin{tabular}{|l|l|l|l|}
\hline 6 madres & $\begin{array}{l}1 \text { primaria completa } \\
1 \text { primaria } \\
1 \text { sin instrucción } \\
2 \text { alfabetizadas } \\
1 \text { superior }\end{array}$ & 3 padrastros/as & $\begin{array}{l}1 \text { primaria incompleta } \\
1 \text { Alfabetizado } \\
1 \text { Superior }\end{array}$ \\
\hline 4 & $\begin{array}{l}2 \text { primaria completa } \\
1 \text { primaria incompleta } \\
1 \text { alfabetizada }\end{array}$ & & \\
padres & & \\
\hline
\end{tabular}

\section{Padre/ madre fallecido}

De una madre se reporta haber muerto por violencia intrafamiliar.

\section{Padre / madre fuera de la ciudad o país}

Dos madres y 5 padres de las 49 familias viven en otra ciudad y/o país.

\section{Lugar de residencia del niño/}

\section{El niño, niña o adolescente al momento se encuentra en:}

Gráfico 11

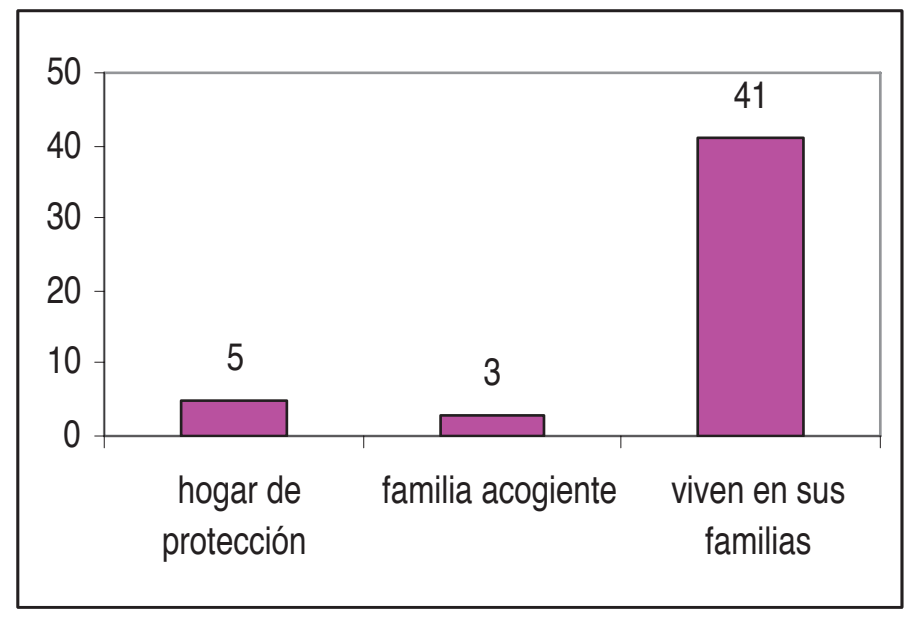




\section{Problemas que afectan al grupo familiar}

Gráfico 12

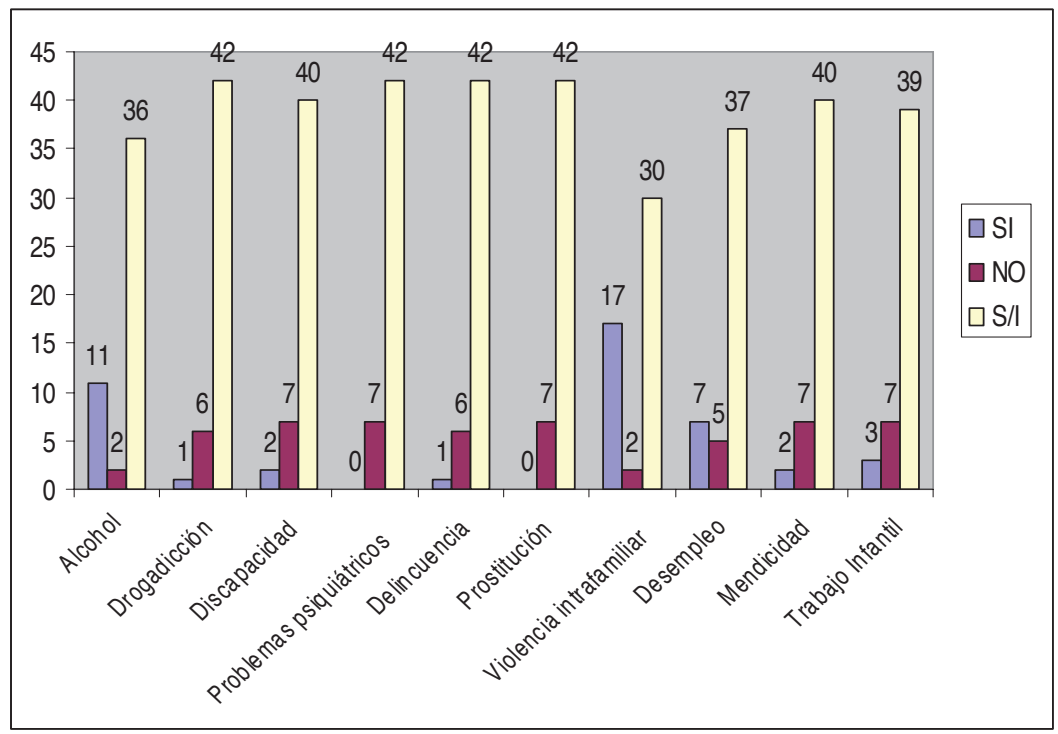

\section{Clase social}

Gráfico 13

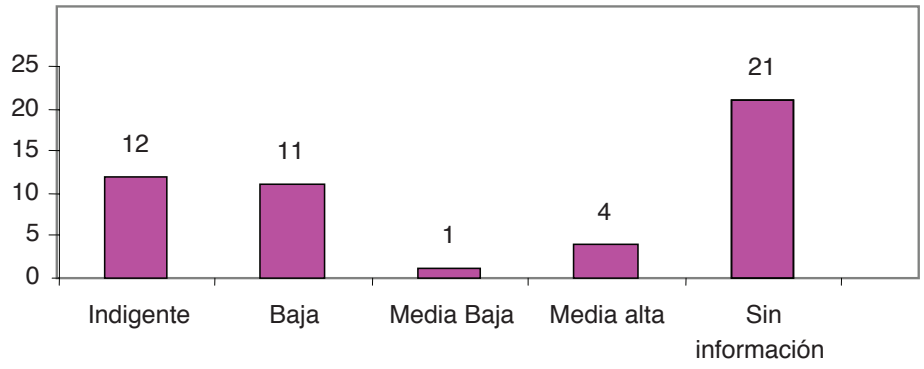




\section{El contexto del abuso}

\section{Caracterización del abuso sexual}

Gráfico 14

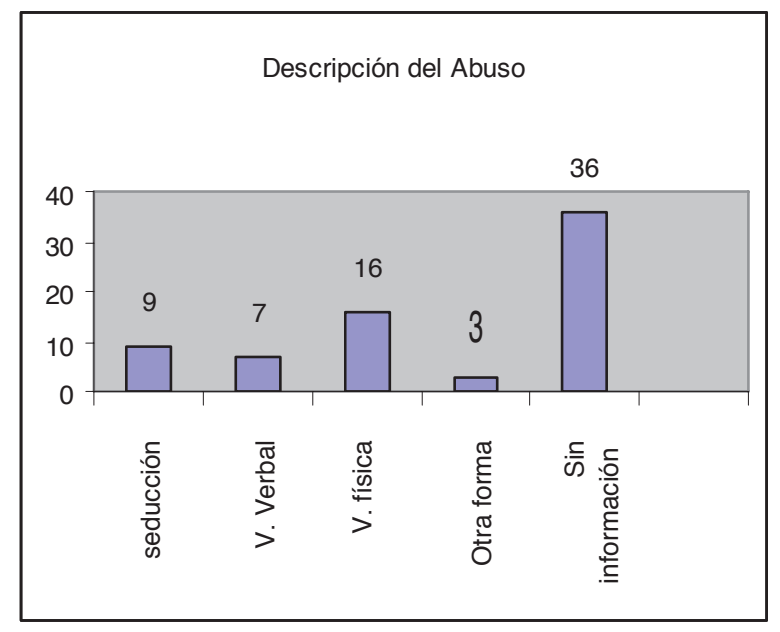

\section{Tipo de contacto}

Tipo de contacto, se considera dos variables: con contacto y sin contacto. Y la persona que da la información.

\section{Gráfico 15}

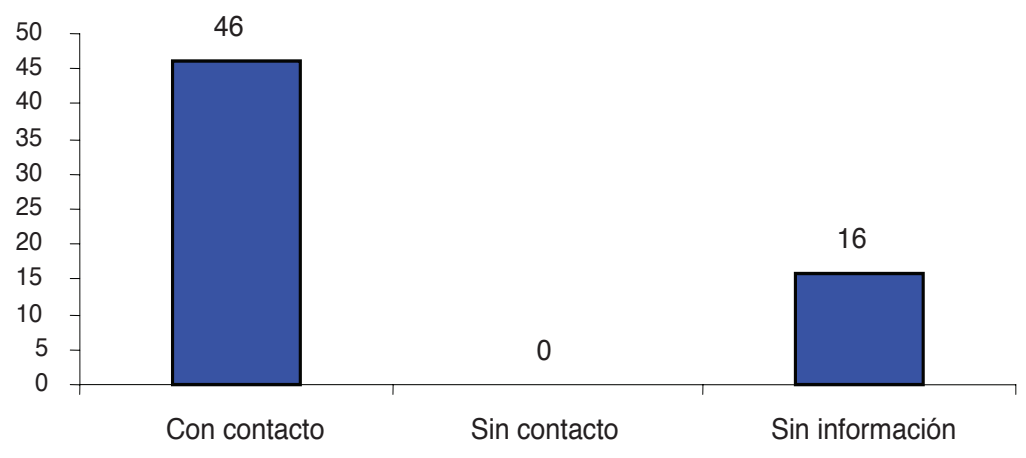


$\underline{\text { Tipo de contacto físico }}$

Gráfico 16

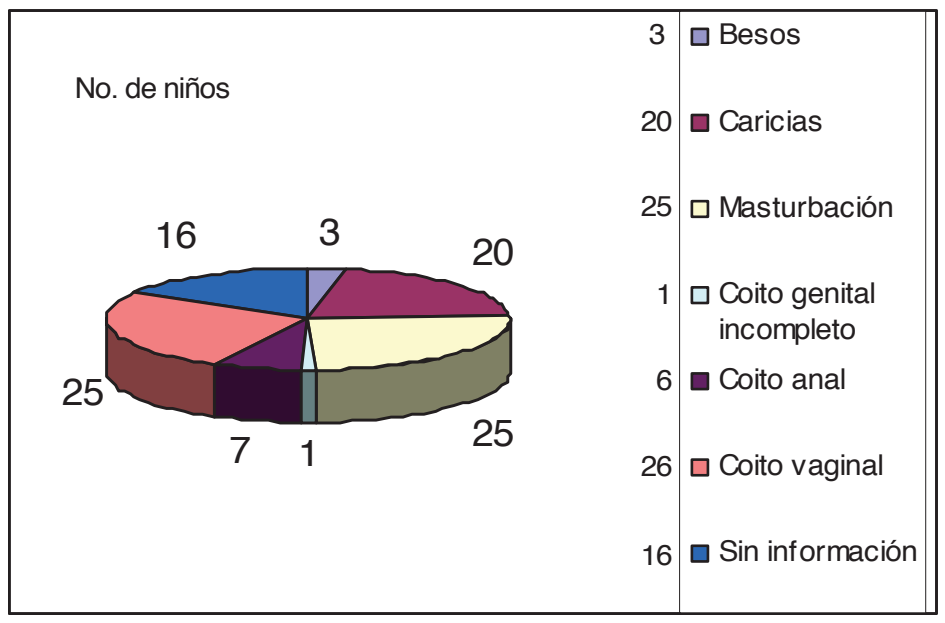

Quién informa el tipo de contacto

Gráfico 17

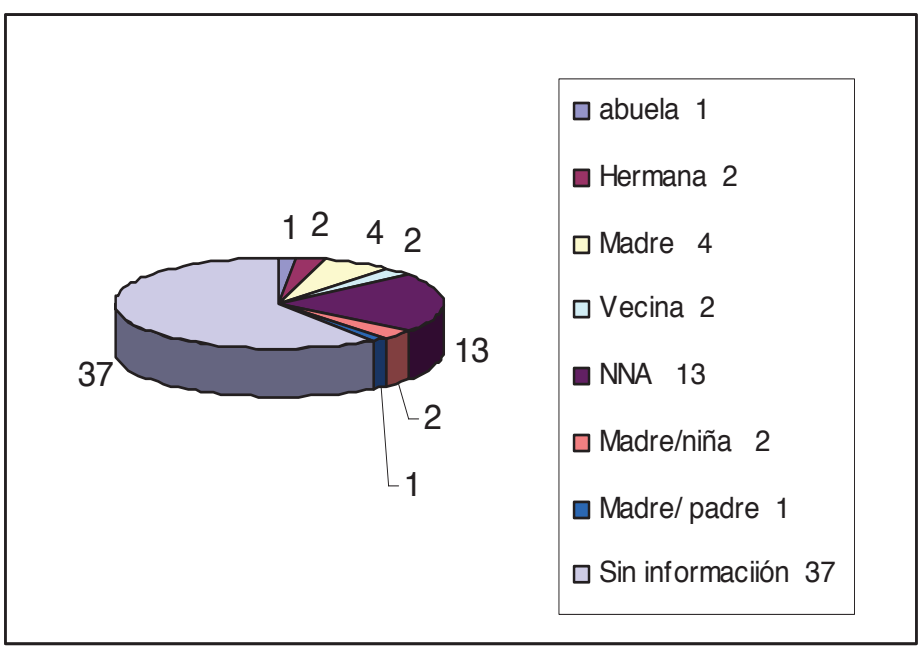




\section{Lesiones físicas producidas por el abuso}

Sí: 9

No: 25

Sin Información: 28

Factores que impiden el desvelamiento

Tabla 3

\begin{tabular}{|l|l|}
\hline Miedo a no ser creído & 2 \\
\hline Miedo a represalias con ella/ él & 16 \\
\hline Miedo a represalias contra sus padres & 2 \\
\hline Miedo hacer daño a sus padres & 2 \\
\hline Miedo hacer daño a sus hermanos & 5 \\
\hline Vergüenza & 5 \\
\hline Ignorancia de la prohibición & 11 \\
\hline Deseo de prolongar esta situación & 0 \\
\hline Protección al agresor & 1 \\
\hline Sin información & 40 \\
\hline
\end{tabular}

\section{Frecuencia}

Una vez: 8

Recurrente: 24

Sin Información: 30

\section{Duración del abuso}

Un episodio: 5

Hasta 6 meses: 7

De 6 meses a un año: 8

De 1 a 2 años: 3

Más de 2 años: 9

Sin información: 30 


\section{Lugar del abuso}

Gráfico 18

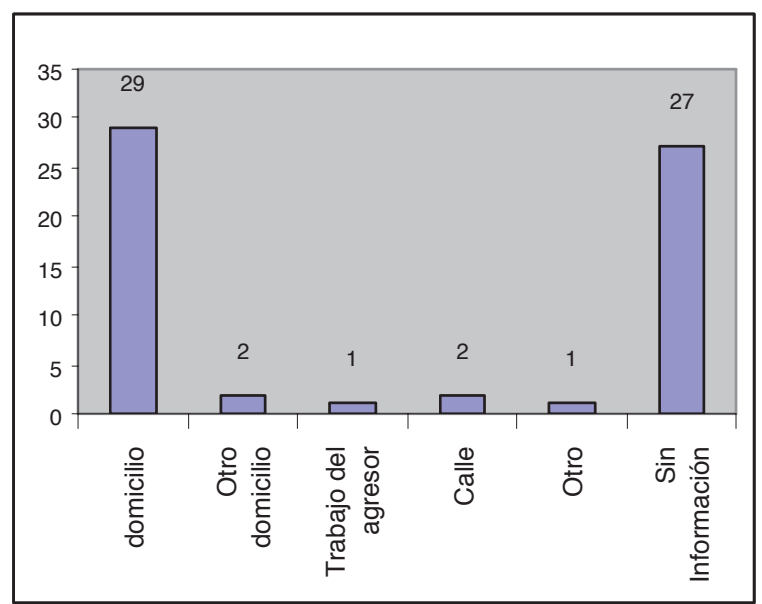

\section{El contexto del abuso desde de la intervención}

Quién conoce el hecho/ Quién denuncia

Gráfico 19

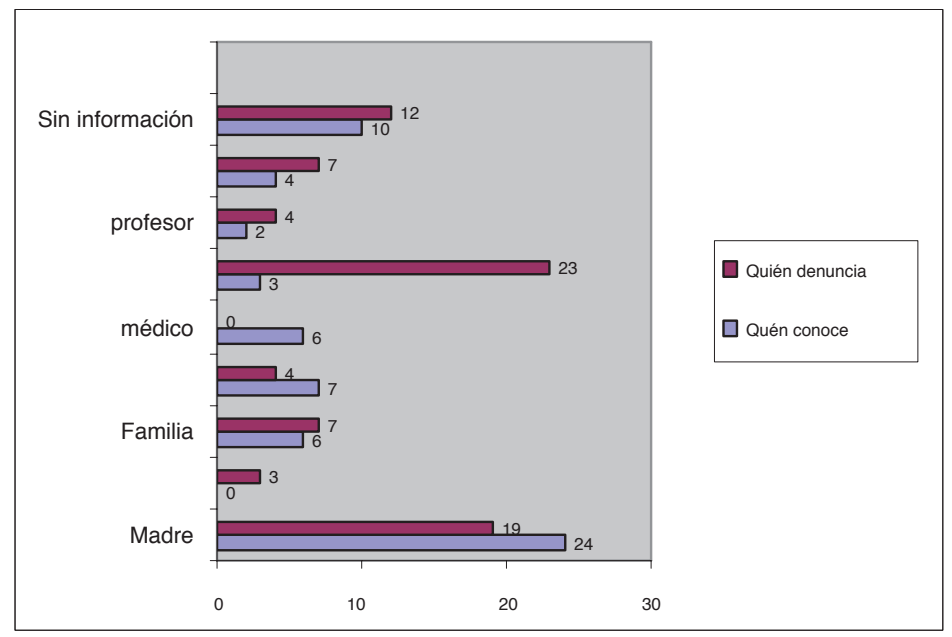




\section{$\underline{\text { Casos con denuncia y con proceso legal }}$}

Sí: 37

No: 14

Sin información: 11

Fue atendida anteriormente por esta misma agresión

Sí: 10

No: 19

Sin información: 27

\section{El perfil de los casos de niños, niñas y adolescentes atendidos por abuso sexual}

La información que a continuación se analiza es recogida en una institución que atiende preferentemente maltrato infantil y abuso sexual, es un servicio gratuito, dirigido a la población de escasos recursos económicos del sector norte del Distrito Metropolitano de Quito. Institución que cuenta con profesionales en psicología, trabajo social y abogados, se conoció que la atención médica se coordina con instituciones cercanas al domicilio de los usuarios.

La información se obtuvo del estudio de 770 casos reportados por maltrato infantil y abuso sexual, desde enero de 2001 a noviembre de 2004,de los cuales 73 casos fueron 'denunciados' por abuso sexual. La información se consiguió directamente de las fichas que la institución posee de cada caso, no se entrevisto a los usuarios, ni a los profesionales. Por tal motivo algunas fichas se excluyeron por no poseer suficiente información para la investigación. El estudio se realiza de 49 casos de los 73 reportados. Se trata de una muestra limitada más que un estudio global, que permitió descubrir algunas problemáticas y tendencias, sin poder precisar su alcance, la misma que con un estudio longitudinal de largo plazo puede ampliar. El perfil social considera 4 categorías: persona agredida, persona agresora, contexto familiar y contexto del abuso, que son entornos y factores que 'intervienen' en el abuso sexual. 


\section{La persona agredida}

Es uno de los 'actores' que intervienen en el abuso sexual. Es la persona que ha sufrido algún tipo de abuso. El análisis se realizó a partir de a la información de 62 niñas, niños adolescentes, lo que corresponde a un total de 49 casos.

\section{Edad y sexo}

Tabla 4

\begin{tabular}{|c|c|c|c|}
\hline Edad & No. niños & Femenino & Masculino \\
\hline 3 años & 1 & 1 & 0 \\
4 años & 4 & 2 & 2 \\
5 años & 5 & 4 & 1 \\
6 años & 7 & 7 & 1 \\
7 años & 5 & 4 & 0 \\
8 años & 7 & 4 & 3 \\
9 años & 6 & 5 & 1 \\
10 años & 6 & 5 & 1 \\
11 años & 4 & 2 & 2 \\
12 años & 4 & 3 & 1 \\
13 años & 3 & 3 & 0 \\
14 años & 1 & 0 & 1 \\
15 años & 6 & 6 & 0 \\
16 años & 2 & 2 & 0 \\
17 años & 0 & 0 & 0 \\
18 años & 1 & 1 & 0 \\
TOTAL & 62 & 48 & 14 \\
\hline
\end{tabular}

En la población estudiada se puede apreciar que las edades en donde se da con mayor frecuencia el abuso sexual es a los 6 años (11\%), un índice alto también se aprecia en las edades de 9 y 10 años y un pique a los 15 años $(9,67 \%)$ en las niñas y adolescentes. Es preciso indicar que la prevalencia es alta entre los 5 y 10 años, en el sexo femenino, lo que representa el 58\% de la totalidad de los casos estudiados. Este índice de prevalencía se da también en los niños, en las edades comprendidas entre 3 y 14 a pesar que la tendencia no es alta, si se pre- 
sentan casos. La frecuencia más alta se da a los 8 años en los niños ( 3 niños)

De toda la población estudiada (62), 49 son mujeres y 13 varones, $79 \%$ y $20,96 \%$ respectivamente.

Al revisar la bibliografía de abuso sexual sobre la edad y sexo, los estudios tienen preferencia por los de orden psicológico, sin embargo indican los agredido/as con mayor frecuencia son mujeres, niñas, niños y que se encuentra en una posición de subordinación. Esta referencia se confirmaría con la población estudiada, puesto que como se aprecia la frecuencia más alta se da en niñas y niños menores de 10 años.

Es preciso resaltar el porcentaje de hombres abusados, si bien es cierto que es bajo, no se puede dejar de mencionar que el abuso a hombres, no deja de ser significativo, tomando en cuenta además que el abuso a niños varones se denuncia mucho menos por ser considerado como vergonzoso.

Ocupación, Instrucción y problemas escolares:

Gráfico 20

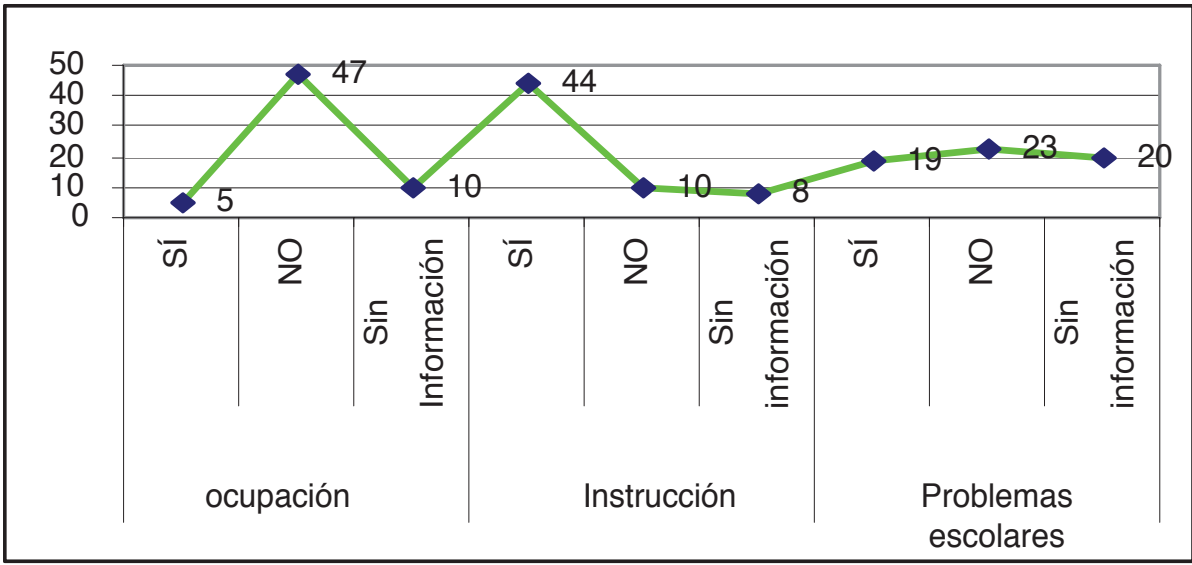

Ocupación. El Código de la Niñez y Adolescencia en el Art. 82 fija en 15 años la edad mínima para trabajar. De acuerdo a esta normativa sólo 9 adolescentes se encuentran dentro de este parámetro. Del total (62 NNA), el 75,8\% no trabajan (47); el 8\% (5) trabaja, la investigación revela que la edad de los niños 
que trabajan son 8,12 , y 16 años, como se aprecia sólo una cumple con la edad establecida en el Código. 16\% (10) sin información.

Instrucción. De los 62 NNA, 57 niños, niñas y adolescentes que se encuentran en edad escolar y, únicamente, 5 NNA tienen entre 3 y 4 años, pese a que en la actualidad es un requisito el prekinder y existe una tendencia marcada a escolarizar al NN a temprana edad. El 16\% (10 NNA) no estudian, en este porcentaje se encuentran los 5 niños que no están en edad escolar y se incluyen a este porcentaje los NNA que han desertado de la escolaridad. El 61\% (38 NNA) tienen educación básica, considerada desde el jardín de infantes hasta el 7mo. año de educación básica. E1 9,67\% están en la secundaria, según la información los adolescentes están entre primero y tercer curso. Es decir, que más del $80 \%$ de NNA tienen algún nivel de educación. El porcentaje sin información es del 12,90\%

En este estudio se considera como problemas escolares a los que tienen relación con: faltas y/o fugas continuas a la escuela/colegio, 'problemas de aprendizaje', Incumplimientos de deberes y tareas, Problemas de relacionamiento escolar con los compañeros, etcétera. El 30,64\% (19) de NNA reportan tener algún problema en la escuela, el 37\% (23) indican que no tienen ningún tipo de problemas, es decir que un poco más de la mitad de los NNA que estudian no presentan problemas escolares. Esta información evidencia que no en todos los NNA se presenta de la misma manera, es posible que para unos este sea un 'Síntoma' para otros no.

De 20 NNA no se tiene información, el 32\%.

Problemas de comportamiento sexual con otros niños y niñas: La definición que hace referencia al acercamiento físico con otros niños o la tendencia a exhibir o mirar el cuerpo. En esta variable se tomó en consideración a niños y niñas de hasta los 12 años. Los NN hasta 12 años son 49. Sin embargo la información se recoge en algunos casos sin considerar la edad. El $16 \%$ de NN se mencionan problemas de comportamiento sexual. Y en el $35,48 \%$ que NO. Estos datos corresponden al 50\% de NNA respecto de los que se tiene información.

En 50\% de los casos no hay información.

Tendencia a escapar de casa, Conductas delictivas, conductas agresivas: 


\section{Gráfico 21}

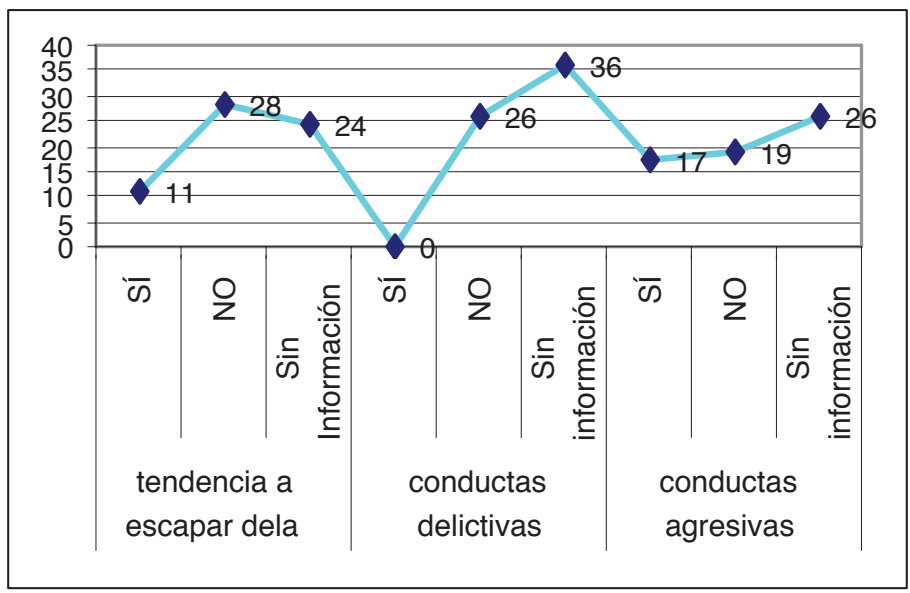

En 17,7\% (11) de NNA se indica tendencias a huir de la casa. En algunos casos se refiere que lo han hecho por evitar seguir siendo abusadas, es importante indicar que el mayor índice se da en adolescentes y sólo 2 son niños de 8 años. Al escapar de la casa se evidenció que no acuden a familiares cercanos, sino que la tendencia es ir a otra ciudad, en este caso vienen a Quito, en busca, sobre todo de trabajo, más que de ayuda. El 45\% (28) señalan que no se han escapado. Del 38,70\% (24) no hay información .

Respecto a la pregunta, si alguna vez han incurrido en conductas delictivas, el 41,9\% (26) dicen que no. En el 58\% no Hay información. Estos porcentajes expresan que más de la mitad de la población estudiada no se tiene información, es decir que este dato no es representativo para afirmaciones.

El 27\% (17) han respondido que si tienen conductas agresivas y 'rebeldes' con sus padres y hermanos sobre todo. El 30,64\% (19) afirman que no tienen conductas agresivas. Un 41,93\% no tiene información. Los porcentajes sin Información en las 3 categorías, son altos, lo que indica que estos datos necesitan ser más tomados en cuenta para la intervención . 


\section{Embarazos}

Del total de la población estudiada (62), son 13 los adolescentes (13-18 años), es decir, el 3\%, del total. De los adolescentes, 12 son mujeres y un hombre. La información obtenida indica 2 adolescentes embarazadas, la una de 15 y otra de 16 años; la joven de 16 tiene retardo mental leve. Es importante indicar que una joven de 15 años, producto del abuso sexual, le extirparon el útero y un ovario. El porcentaje sin información corresponde al 3\%. 58 NNA incluidos niños, niñas y adolescentes hombres reportan NO embarazo.

\section{Discapacidad}

La discapacidad reporta el $2 \%$ de los casos. Las dos personas son mujeres y una de ellas de 15 años con retardo leve, como consecuencia del abuso quedó embarazada. El 8\% de los casos no tienen información.

\section{Enfermedades}

Esta variable se tomó en cuenta a las enfermedades que se produjeron por el abuso sexual o las que reportaron los NNA y por las cuales fueron a consulta médica. El 51,61\% no presenta enfermedades. En un 10\%, expresan tener alguna enfermedad. Se encontró: desnutrición en una niña de 10 años. Enuresis una niña de 6 años, la enuresis a menudo está ligada a cuestiones de abuso sexual. La mitad de los casos reportan dolores estomacales y diarreas frecuentes y a raíz de esta dolencia acudieron al servicio médico, en donde se detecta el abuso sexual. Infecciones vaginales en $3 \mathrm{NNA}$, incluidas enfermedades venéreas, sin incluir en este número a una joven que le extirparon el útero y un ovario. El porcentaje del $10 \%$ en su mayoría son mujeres, en un solo hombre se presenta enfermedad, se trata de un niño de 6 años, que tiene dolores estomacales y diarreas frecuentes.

Número de agresores por cada niño, niña o adolescente abusado y relación con el agresor: 
Gráfico 22

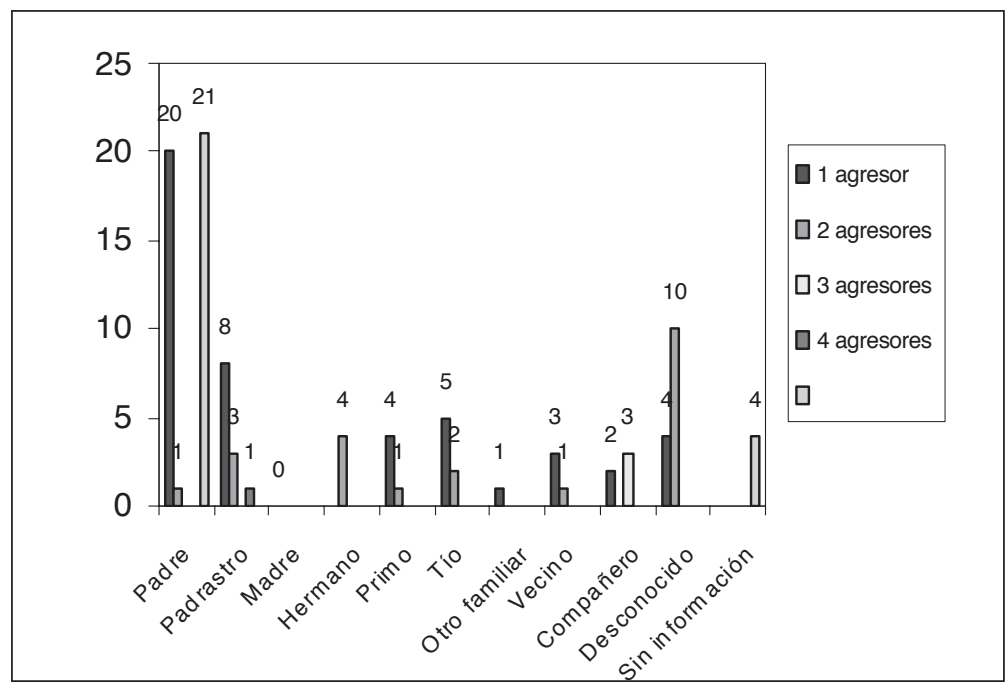

El cuadro articula la relación con la agredida con el número de agresores. Si bien los datos respecto al agresor fueron tomados por cada caso, hay que tomar en cuenta hay NNA que fueron abusados por más de 2 agresores, lo que explica por qué sumando tenemos un total de 75 personas agresoras. De la muestra el $77,41 \%$ (48 NNA) fueron abusados por un solo agresor. En el 16\% (18 NNA) fueron abusados por 2 agresores. En el 1,6\% (fueron abusadas por $3(1,6 \%)$ ) por 4 agresores. Del 2,5\% no hay información

Es decir, que 19,2\% los NNA han sido abusados por más de 2 agresores.

Cabe precisar que dentro de este grupo se encontró: 1 niño de 9 años fue abusado por 2 personas; 1 niña de 6 años. En el resto de casos se trata de adolescentes mujeres (18).

La relación que la víctima tiene con el agresor hace referencia al abuso sexual intrafamiliar y extrafamiliar. Intrafamiliar cuando el abuso es cometido por: madre, padre, hermanos, abuelos, tíos, y para algunos autores padrinos. Y extrafamiliar cuando el abusador es 'desconocido para el niño', sin embargo, como veremos más adelante la investigación muestra que los 'desconocidos', son personas que generalmente se encuentran muy cercanas a la familia de la víctima. 
El abuso intrafamiliar se presenta de la siguiente manera: el padre aparece como abusador en el 27\% (21padres). A este porcentaje hay que agregar 15,58\% corresponden al padrastro, lo que indica que $45,58 \%$ (33 padres/padrastros) corresponde al jefe de familia o por lo menos la persona, que representa la figura paterna en la familia 5\% (4) son hermanos, 7,79\% (6) primos, 7,79\% (7) tíos, 1 otro familiar.

Con relación al abuso extrafamiliar corresponde a: vecinos el 5,19\% (4), compañero $6,49 \%$ (5), desconocido $18,18 \%$ (14), otro $1,29 \%$. Total de $31,15 \%$.

Sin información el 2,59\%, se trata de dos casos en los cuales no se tiene información en todos los ítems. De los 77 agresores, 51 son miembros de la familia, es decir el 66,23\% corresponde a abuso intrafamiliar, en relación al abuso extrafamiliar que es el 31,16\% (24).

Nota: un caso reporta que la joven fue drogada para ser abusada, el agresor es desconocido.

\section{La persona agresora o abusadora:}

En función del grupo total de 62 NNA, podemos mencionar que existen 7 grupos de hermanos/as, este grupo suman 20 NNA. 12 niños fueron abusados por más de dos agresores. Por ello la información que se presenta corresponde a un total de 77 agresores. Con respecto a la categoría 'persona agresora' la información se limita a datos generales, y los otros ítems contemplados para el estudio la información es limitada y/o sin información, por lo que el análisis no se ha realizado en porcentajes.

\section{Sexo y edad}

Con respecto al sexo, de la totalidad de la población estudiada (77), 56 agresores son hombres, no existe información sobre abusadoras mujeres. De 19 agresores no hay información con respecto al sexo. Sin información en casi todos los casos se puede presumir por la información que son hombres. 
La edad de los agresores va desde los 10 hasta los 60 años, el mayor número de agresores se da en el rango de 31 a 40 años (15 agresores); es decir, que son adultos jóvenes y que por nuestra cultura generalmente se encuentran casados o con pareja medianamente estable, sin embargo como veremos posteriormente no se tiene suficiente información sobre el estado civil, además que se considera que es una edad en la que se ha independizado económicamente. Entre los abusadores se encuentran 4 niños, de 10 a 12 años.

\section{Instrucción}

En esta variable, los datos corresponden a 22 agresores, 11 de ellos, con educación básica, siendo éste el número más alto. 55 agresores sin información

\section{Estado civil}

La información corresponde al estado civil en el momento del registro y en otros casos indican que estuvieron por ejemplo casados, registrando de esta manera esa información. Se consideran en esta condición: casado, soltero, separado, Unión libre, divorciado y viudo.

De 26 agresores se tiene esta información: 6 casados, 4 solteros, 5 separados, 4 Unión libre, 2 divorciados, 5 viudos, 51 sin información. Igualmente, el ítem correspondiente a sin información es alto, de 55 agresores.

\section{Ocupación}

Con respecto a la ocupación: 48 casos no tiene información; 18 casos no trabajan; 11 casos si trabajan. Es preciso tomar en cuenta que 15 agresores son menores de 18 años; 6 de ellos reportan que estudian, 3 adolescentes indican no trabajar que no traban pero no existe información sobre si estudian o no. Según estas cifras se presume que existe entre los agresores un alto porcentaje de personas adultas que no trabajan. 


\section{Discapacidad}

Se registra información de 5 casos: 2 personas que no tienen ninguna discapacidad, y 3 personas que sí tienen discapacidad. 72 casos no hay información. Es decir que en esa variable se tiene poca información.

\section{Enfermedad}

Se tiene información de 7 personas: 6 indican que si tienen una enfermedad, 2 de ellos enfermedades venéreas. Los otros casos indican enfermedades, pero no se reporta de que tipo. Uno no tiene enfermedad. 71 agresores sin información.

\section{Problemas de alcohol}

Se escucha frecuentemente que las familias justifican un hecho de abuso sexual indicando que el agresor estuvo 'chumado y no sabía que hacía', sin embargo, la poca información no permite confirmar o negar la Teoría de estas familias; 62 personas agresoras sin información; 13 personas refieren tener problemas con el alcohol. No existen datos sobre la variable que NO tiene problemas con el alcohol.

\section{Problemas con las drogas}

En esta variable la información de personas es limitada. En 2 casos que el agresor tiene problemas con las drogas, sin embargo, los 2 corresponden a una sola persona que abusó de 2 hermanos; el agresor en este caso era el padre, quien era divorciado y al momento del registro los dos niños estaban bajo su cuidado. En 75 casos no se tiene información.

\section{Historia de abuso}

En un grupo de 5 hermanos se refiere que el agresor (padre) tiene una 
historia de abuso sexual, en el mismo caso que la madre murió por violencia doméstica.

\section{Reincidencia en abuso sexual}

Se tiene información de una persona de 21 años, que es reincidente en abuso sexual. Sin embargo, es necesario mencionar que los datos de la investigación muestran que existen grupos de hermanos que fueron abusados sexualmente por la misma persona y esta información no se registra.

\section{Antecedentes de denuncia por abuso sexual}

En casos atendidos en esa institución existe un alto índice de proceso legal, auspiciado por la misma institución. Esto indica que en la institución rige la observancia al Código de la Niñez y Adolescencia y el Código Penal en este tema. Sin embargo, no se registra antecedentes de abuso, la denuncia se la hace por el caso que solicitó intervención.Un solo caso fue denunciado por abuso sexual, se trata de una joven agredida por 3 adolescentes, no se tiene información si se llegó a juicio.

\section{Antecedentes penalizados por abuso sexual}

En el estudio solo se presenta un caso penalizado, es un padrastro de 30 años. No existe información sobre el proceso legal. Y no hay referencia del proceso legal en el caso que apoyó este centro.

\section{Antecedentes delincuenciales}

Se reporta un solo caso en el que los agredidos son 2 hermanos, en donde el agresor es el padre, y está vinculado a antecedentes delincuenciales y tiene problemas con drogas y alcohol. 


\section{Organización y estructura familiar}

Se han estudiado 49 familias que corresponden a los 62 NNA.

\section{Organización familiar}

Tipo de familias; Jefatura familiar; Estado civil de los padres.

El análisis se realiza independientemente del lugar de residencia de los niños, se consideró la relación de consanguinidad o cuando la madre ha constituido una relación relativamente estable con su pareja.

GRÁFICO 23

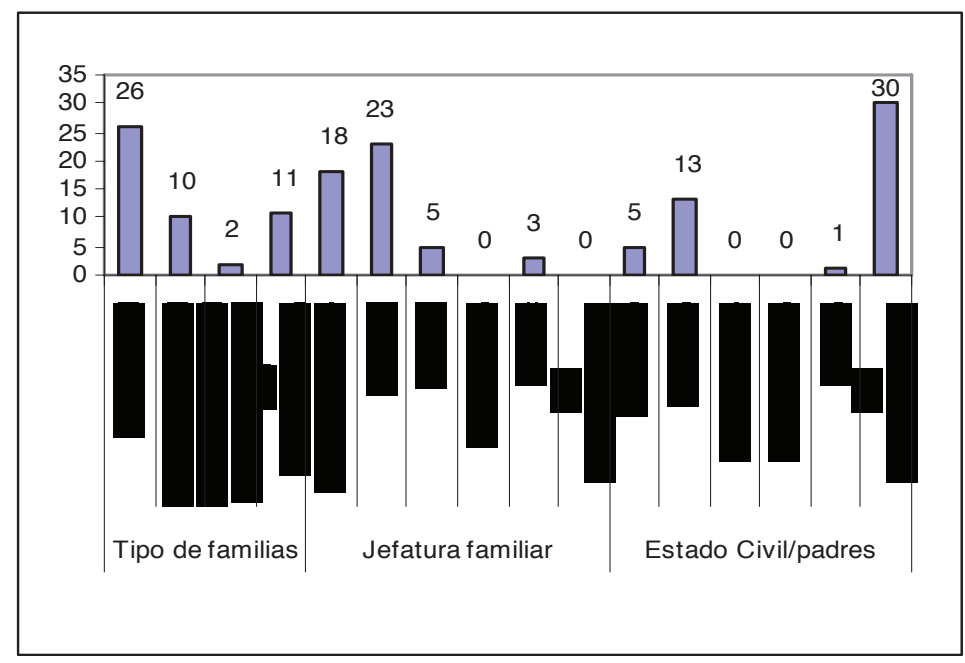

La información obtenida indica que de las familias estudiadas: 26 son conyugales, es decir que viven padre, madre e hijos; 10 familias son monoparentales, uno de los padres vive junto a sus hijos; 2 familias son monoparentales con allegados, es importante indicar que estas 2 familias en la una la abuela materna tiene bajo su cuidado a la nieta, y ésta vive con sus hijos solteros. La otra familia es un padre solo a cargo de 5 hijos, y una tía de los niños de 17 años ejerce el rol de madre. La conyugalidad de las familias, no indica necesariamente que la jefatura sea compartida. En 23 familias que es cerca de la mitad de las familias estudiadas la tendencia es jefatura femenina, en algunas 
de ellas la separación vino luego de descubrir que su pareja abusó de sus hijos; 15 de ellas tiene pareja, que en algunos casos viven juntos y en otros son parejas no establecidas. En 18 familias la jefatura la ejercen padre y madre o por lo menos viven juntos, sin embargo en algunos casos la manutención de los hijos está a cargo de la madre. En 5 familias el padre es quien tiene la jefatura familiar, uno de ellos tiene pareja. En 3 familias la jefatura familiar la ejercen otros, así por ejemplo, en uno de los casos una tía de 17 años asumió esta responsabilidad luego de la muerte de la madre de los niños y en el otro caso vive con la abuela, los 2 padres viven en Estados Unidos; en el otro caso, una joven de 13 años que huyó de la casa, primero vivió con una tía y luego con el novio. Algunos NNA, se encuentran viviendo con familias acogientes u hogares de protección.

El Estado civil de los padres, Sin información en este ítem es alto 30 familias, la información obtenida indica que 13 padres/madres son solteros, se presume que la tendencia en esta población es la Unión Libre, por el tipo de familia, 26 son conyugales y únicamente 12 familias son monoparentales, sin embargo, en Unión libre la información es cero.

\section{Número de hijos por cada familia}

Es preciso indicar en estas 49 familias que en 8 el abuso es reiterativo y se abusa a más de 2 NNA. La tendencia actual es familias cortas, tienen 2 ó hasta 3 hijos, en el estudio dos familias tienen 2 hijos cada una, pero la tendencia es que 10 y 14 familias tienen entre 3 y 4 hijos, lo quiere decir que en familia viven alrededor de 5 y 6 personas; aunque el número no es alto, 5 familias tienen 5 hijos y otras 5 familias, 6 hijos; 3 familias tienen 8 hijos; 2 hijos tienen 2 familias; y, 7 hijos tienen otras 2 familias.

\section{Edad de los padres, instrucción, padre/madre fallecido, fuera de la ciudad}

Edad de los padres: en la edad de los padres no existe información de 12 familias. Fluctúa entre 26 años y 44 años la edad de los padres. Y de las madres entre 23 y 50 años. La edad de las familias donde viven los 2 padres o alguno de ellos con pareja que son 26 en 9 parejas la edad de la madre es superior a la de su pareja. 
Instrucción de los padres o representantes: esta información es reducida, se obtiene información de 9 familias que corresponde a 13 padres, madres y padrastros; 3 tienen primaria incompleta; 3 primaria completa; 2 sin instrucción; 2 alfabetizados; y, 2 con educación superior. En esta variable no se puede apreciar una tendencia por la poca información.

Padre/madre fallecido: en una de las familias de las 49 se reporta que una madre murió producto de violencia intrafamiliar.

Padre/madre fuera de la ciudad o del país: en 6 familias existe esta información. En un solo caso la niña no vive con la madre, ésta vive en otra provincia, en 4 familias los padres son los que están fuera de la ciudad, una de estas familias, la madre huye con sus hijas y se cambian de ciudad, y en un solo caso los dos padres están fuera del país.

\section{Lugar de residencia del NNA}

En 3 familias los niños viven en familias acogientes. En un caso la niña huye y es acogida por un señor y su hijo, ahí se queda a vivir algún tiempo, en los otros 2 casos las adolescentes se encuentran como empleadas domésticas; en uno de ellos la joven huye por el abuso sexual del padrastro y en el otro caso no hay información sobre la familia y el agresor. En 5 familias sus niños viven en hogares de protección así: 2 casos se reportan por la institución donde se encuentran los niños, no se conoce el motivo de ingreso de los niños al hogar, la información familiar y del agresor, en un caso, es poca y en el otro no existe. En 3 casos los niños y adolescentes ingresan al hogar de protección para romper el abuso sexual, producto de la intervención institucional. En un caso existe un grupo de 3 hermanos. En 41 familias los niños se encuentran viviendo ahí, no se sabe las condiciones o si el abuso paró, considerando que un gran porcentaje los agresores son padres y padrastros, en muy pocos casos la madre toma la decisión de separarse luego de conocer el abuso sexual.

\section{Problemas que afectan al grupo familiar}

Uno de los hechos que más llama la atención es el alto número sin información fluctúa entre el 30 y 42 de las 49 familias, tomando en cuenta que los problemas de grupo familiar pueden considerarse como factores de riesgo o factores de 
vulnerabilidad que incidan para que se de un hecho de abuso sexual. El estudio indica que en 17 familias existe Violencia intrafamiliar, específicamente violencia de pareja. En 11 familias el padre o padrastro consume alcohol, en 2 familias los 2 padres son alcohólicos. Y en uno de los casos la que consume alcohol es la agredida, una adolescente de 15 años, quien vive con la abuela materna.

\section{Clase social}

Los rangos de clase social, fueron tomados de acuerdo a las categorías establecidas por el equipo que trabaja con esta población. No se conoce criterios para determinar la clase social. Es importante considerar que la población objetivo de esta institución es de preferencia la de 'escasos recursos económicos', sin embargo, ésta no es una condición para brindar el servicio. La mayoría de proyectos de atención y prevención de violencia tienen esta característica. El mencionar la clase social dentro de la investigación permitirá no sólo cuantificar o clasificar a las familias, sino de alguna manera contextualizar al maltrato y desmitificar la concepción de que el maltrato es sólo intrafamiliar y aceptar la idea de la responsabilidad social. Varios autores afirman que la situación económica dentro del maltrato es considerada como un factor de riesgo, esto articulada a la concepción del niño 'cosa', representan gastos para la familia y el Estado o que son impedimentos para cumplir objetivos o sueños.

La investigación muestra que la población que acude a esta institución son las familias de clase baja, media e indigentes ( 24 familias) y 4 familias consideradas dentro de la clase media alta. Sin información 21 familias. Posiblemente estas cifras representen el perfil poblacional de la institución, porque 'la violencia que se inflige a los niños no es privativa de ninguna clase social'. (Barudy, 1993). Y es posible que en familias de 'clase alta' la violencia y abusos a los niños quede en la impunidad, por preservar la 'unidad o reconocimiento familiar'.

\section{Contexto del abuso sexual}

El Abuso sexual entendido como (OMS de 1986) "la explotación sexual de un niño implica que éste es 'víctima de un adulto', o de una persona eviden- 
temente mayor que él, con fines de satisfacción sexual", tiene entre otras las siguientes características que se estudian y que prevalece como la: seducción, violencia verbal, física, entre otras, factores que no siempre se dan solos sino que tienen relación entre ellos y con otros.

\section{Caracterización del abuso sexual}

La seducción con la manipulación del NNA con regalos, obsequios, haciendo uso de la confianza o cercanía del NNA o de su familia. La violencia física o verbal y otras formas, son formas que hacen que NNA sienta que tienen que hacerlo e incluso mantener el silencio. La cifra más alta es sin información 36 NNA. En 23 NNA se da con violencia verbal (7) y física 16) y con seducción 9.

\section{Tipo de contacto}

Es preciso indicar que el abuso sexual es una forma visible del maltrato, sin embargo no siempre es evidente físicamente, la investigación encontró que en 49 NNA, el abuso mayoritariamente se produjo con contacto. Sin contacto en ningún caso, este dato posiblemente demuestre la tendencia de la población que se atiende en este servicio, la prostitución, el exhibicionismo y todas las formas de pornografía, son casos para ser atendidos en otras instancias. Y en 16 NNA sin información. Con relación al tipo de contacto físico en el abuso sexual en 26 niñas y adolescentes se produce el coito vaginal, en 7 niñas y niños coito anal, de éstos en 3 casos el coito anal es a hombres y en 4 casos a niñas y adolescentes. Se observa generalmente que el abuso a los hombres no existe besos, y en la gran mayoría existe caricias y masturbación.

En segundo orden se encuentra la masturbación; 25 más un caso en el que se produce un coito genital incompleto, seguidamente de las caricias (20). En pocos casos se muestra que el NNA acaricie o masturbe al adulto agresor.

Generalmente se evidencia que el agresor acaricie o masturbe al NNA. Una cifra alta es Sin información 16.

Estas cifras confirman lo que la bibliografía indica, que previo al coito, durante algún tiempo se produce gestos y acciones de seducción. En el 40,32\% coito vaginal y el 11,29\% coito anal, es decir que más de la mitad de los NNA 
se da el abuso sexual con coito, si es importante indicar que éstos indicadores en los niños no se presentan uno solo, sino uno o más de ellos.

Quién informa del tipo de contacto, un dato representativo es Sin información 37 NNA, seguido de que el que informa es el NNA en 13 casos, más 2 casos en los que informa conjuntamente con la madre (15). En 8 casos informan familiares cercanos abuela, hermana, madre, padres. $Y$ un dato interesante es el que reporta las vecinas en 2 casos.

\section{Lesiones físicas producidas por el abuso}

Las consecuencias físicas del abuso sexual, son daños físicos que dejan marcas que pueden llegar a ser irreparables. No en todos los casos son visibles como los manoseos. El estudio investigó las lesiones físicas, con los siguientes resultados: 25 NNA reportan no tener lesiones físicas; 9 que el abuso si produjo lesiones físicas, como desgarros vaginales y anales, infecciones vaginales, por contacto sexual, enfermedades venéreas, enuresis, y extirpación del útero y un ovario. Algo que llama la atención es que en 5 NNA se presentan frecuentes dolores estomacales, motivo que los llevo al médico y allí se descubre que fueron abusados sexualmente. A pesar que el embarazo no es una lesión, si es importante mencionar en esta parte que 2 adolescentes producto del abuso sexual quedaron embarazadas.

\section{Factores que impiden el desvelamiento}

Considerando que el abuso sexual generalmente se da en un contexto donde el silencio y el secreto priman, es primordial el reconocimiento de los factores que impiden el desvelamiento. La investigación indica que de 40 NNA sin información, en 16 NNA refieren tener miedo a represalias contra el/ella, seguramente se da en el marco del secreto y protección a la familia. Seguidamente se presenta en 11 NNA ignorancia a la prohibición, este dato no indica la ignorancia de los NNA, sino representa una cultura, en la que el maltrato y los abusos, son atribuidos a la responsabilidad de los NNA; 5 indican tener vergüenza; 5 NNA tienen miedo hacer daño a sus hermanos; 2 NNA refieren tener miedo a no ser creídos; 4 NNA revelan que tienen miedo a represalias o hacer daño a sus padres. Y un solo caso muestra el deseo de proteger al agresor. 
La frecuencia del abuso muestra que en 24 niños es recurrente y un solo episodio 8 NNA, esta información muestra una tendencia frecuente que las familias que denuncias lo hacen cuando los hechos se han producido por más de una vez, o la develación ocurre posterior a una crisis, y toda la familia entra en crisis y es cuando el NNA lo devela.

30 NNA, sin información.

Duración de abuso, 30 NNA, refieren Sin información, es decir que un poco más de la mitad de la población tiene información; 27 NNA muestran que han sido víctimas por varios meses hasta más 8 años, y en 5 NNA se habla de un solo episodio. Esta información revela, sin ser contradictoria, es necesario articular con la frecuencia en la que muestra que 8. NNA dicen de una vez. En relación al lugar dónde se produce el abuso sexual, revisando los resultados indican dos tendencias sobresalientes: la primera es que el lugar de preferencia para cometer el abuso sexual es el domicilio del NNA (29). Y el segundo es el Sin información 27 NNA. Las otras categorías presentes en la investigación son: otros domicilios, que generalmente son domicilios o lugar de trabajo de los agresores y la calle y otro (hotel), suman un total de 6 NNA. Articulando este dato a la información de la relación con el abusador, probablemente se explique, porque la mayoría de los abusadores son miembros de la familia y el lugar más seguro para cometer el abuso es el domicilio.

\section{Contexto del abuso sexual desde la intervención}

El objeto de la investigación es determinar un perfil psico-social, por tal razón se obvia lo relacionado a la intervención legal y su afectación en NNA y la familia, cuando son parte de este proceso. En términos generales todas las formas de violencia generalmente no se denuncia, las personas saben que son procesos largos, en los que no existe protección real y un seguimiento que garantice un tratamiento integral a todos los entornos Es importante puntualizar que en instituciones de atención de maltrato y violencia hablar de denuncia no refiere precisamente a una denuncia legal, sino que se orienta a "poner en conocimiento" para solicitar ayuda (sugerencias, consejos, orientaciones, etc.), que posteriormente puede conducir a que se realice una denuncia legal e iniciar este proceso o para un apoyo sico-social al NNA y/o la familia. 
Es necesario mencionar lo que establece el Código de la Niñez y adolescencia sobre la obligatoriedad de la denuncia, Art. 72 "las personas que por su profesión u oficio tengan conocimiento de un hecho que presente características propias de maltrato, abuso y explotación sexual, tráfico, pérdida de que hubiere sido victima un niño, niña o adolescente, deberán denunciarlo dentro de las veinticuatro horas siguientes de dicho conocimiento ante cualquiera de los fiscales, autoridades judiciales o administrativas..."

La investigación revela que de los 62 NNA de 49 familias estudiadas sólo 37 NNA tiene denuncia con proceso legal, sin especificar el proceso y si existe sentencia o no. Así mismo se puede observar que en los casos que el abuso se ha cometido a hermanos, todos tienen denuncia legal. De 14 niños no hay denuncia y 11 sin información. Estos datos dan cuenta que el mandato legal no se cumple a cabilidad. Será parte de otro estudio, entender los factores o causas del incumplimiento.

Entre quien denuncia y quien conoce el hecho el porcentaje más alto esta en la madre, 24 madres conocen y 19 lo denuncian, en algunos casos aunque ella no es la que conoce el caso, pero asume la responsabilidad de denunciar y/o solicitar ayuda y en algunas con el apoyo de la institución. Es preciso indicar que la madre conoce por versión de su hijo/a. En segundo lugar se encuentra la institución como la que denuncia, y no tanto la que conoce, en este caso se presume que la institución es la que realiza la denuncia legal. En el estudio se puede apreciar que cuando existe intervención institucional para la denuncia, el caso es conocido por varias instituciones, por ejemplo la investigación muestra las que mas intervienen son INNFA y sus proyectos, DINAPEN, Defensoría del Pueblo, Fiscalía, entre otras, más las instituciones de donde se reportan los casos. Otro dato relevante es cuando el abuso es conocido por el personal de salud. El estudio indica que el abuso de 6 niños es conocido por un médico y contrariamente a lo que indica el Código de la Niñez y Adolescencia, el médico no realiza la denuncia, por la experiencia se sabe que la denuncia delega a la Trabajadora Social o al educador. No sucede lo mismo cuando conoce un profesor, en este caso, el profesor conoce el abuso de 3 NNA y denuncia en 4 situaciones.

Sin embargo es importante mencionar que los NNA que fueron atendidos anteriormente por abuso sexual, el estudio indica el número más alto es el Sin 
información 27 NNA, 19 indican que NO han sido atendidos anteriormente y 10 niños fueron atendidos anteriormente por abuso sexual, estos datos muestran posiblemente dos cosas, la poca investigación en relación a los antecedentes de abuso o que al ser la primera vez que acuden esta información no se registra.

\section{Conclusiones y recomendaciones}

El presente estudio trata de contribuir a documentar la problemática del Abuso Sexual, lo que permitirá comprender y fundamentar formas de atención e intervención que sean propias de esta realidad, porque solo conociendo se brindará pistas a las profesionales en la intervención y al Estado para la formulación de Políticas sociales y su aplicabilidad. Uno de los resultados de la investigación ha sido la insuficiente información, sobre todo en referencia al agresor. Existe escasa referencia a datos generales de identificación. Esta tendencia hace presumir: 1) que la intervención esta dirigida exclusivamente a NNA, es decir para protección y 2) la posibilidad de que exista un sesgo en relación al agresor en la intervención. Estas presunciones hacen pensar que la intervención respecto al agresor es limitada o focalizada; es decir que tiene sesgo punitivo y sancionador, lo que puede dar lugar a que el agresor quede fuera de la intervención socio-terapéutica, dejando de lado la posibilidad de una rehabilitación y dificultando de esta manera romper el círculo de abuso. Sería conveniente idear y realizar registros de contextualizaciones más puntuales; datos que permitan realizar estudios, con los que establecer políticas en temas específicos.

Al no registrarse historias de abuso, se podría explicar el abuso desde una relación de victima y victimario exclusivamente, cuando en realidad las historias de abuso es un factor que explica y guía las posibilidades de recuperación en los actores involucrados en situaciones de abuso sexual, sin restar la importancia y responsabilidad de los adultos por acciones cometidas sobre los NNA. Las estadísticas generales en relación al abuso indican que los porcentajes más altos es sufrido por niñas, "se estima que el $23 \%$ de niñas y el $15 \%$ de niños sufren abuso sexual, antes de los 17 años". A. Criville (1994) indica 2 picos a los 5-6 años y 14 años (p. 11). Así lo confirma el presente estudio: 79\% de mujeres, en relación al 20,96\% de varones. Considerando que del total de la población estudiada, con relación a los agresores (77), 56 son varones y 21 
sin información En mi práctica profesional como trabajadora social, he recibído más mujeres que hombres que soliciten ayuda u orientación para denuncia legal, este hecho puede ser discutible al momento de establecer las cifras en relación al género, es complejo cuando el agredido es hombre. Volviéndose complicado establecer cifras reales con relación a cuántos varones han sido abusados y cuántas mujeres son abusadoras sexuales. Predomina la visión de vulnerabilidad de las mujeres. Es importante una perspectiva de intervención interdisciplinaria e integral, para evitar sesgos profesionales o de género. 12 NNA reportan que han sido 'víctimas' de abuso sexual por más de 2 abusadores y la poca información sobre el desvelamiento del abuso sexual hace que se presuma una prevalencía de la subordinación de los NN ante los adultos, esto puede referirse a la dificultad de socialización que actualmente viven los niños, es decir la temprana separación del NN de la familia, hace que confronte normas y valores que provienen de otros espacios sociales, lo que contribuye a construir una identidad poca definida y genera desconfianza en sus propias capacidades, también influye el sistema.

El estudio recoge información sobre 49 familias, de estas en 7 familias el abuso es reiterativo, aunque en la información proporcionada en la categoría reiterativo es limitada. El estudio reafirma investigaciones hechas en otros contextos, que indican que acciones violentas y abusivas están al interior de las familias y vienen dadas por los propios padres o referente paterno (2). La información expresa que 51 personas agresoras son miembros de la familia y 24 no son miembros de la familia. Dado que la cantidad de casos son de carácter incestuoso, es conveniente que los profesionales que atienden estos casos trabajen en estrategias preventivas, en las cuales se especifique el papel del adulto, su responsabilidad como padre, madre, promoviendo así relaciones familiares saludables en donde exista una clarificación de roles dentro de la familia y romper los mitos y tabú del incesto.

Si bien es poca la información sobre la tendencia a escapar de la casa. Del total de la población el $17,7 \%$ indican que han huido de la casa, sobre todo para evitar el abuso sexual, el mayor número de casos se dan en adolescentes mujeres. Seguramente este hecho se produce por la poca o ninguna decisión de la familia por develar, la información indica que en muy pocos casos la madre toma la decisión de separarse. 
Otro aspecto relevante es la intervención de varias instituciones en un mismo caso. La investigación muestra que cuando se trata de casos denunciados, en la intervención han participado varias instituciones de orden legal, policial o de defensa de derechos. No se visualiza o no se menciona el apoyo psicoterapéutico a los involucrados en el abuso sexual. A este hecho es preciso agregar que en los casos denunciados el abuso es recurrente y existe mucha fragilidad en los NNA y la familia. La coyuntura de la denuncia se produce en medio de una crisis familiar y NNA necesitan apoyo, que permita una orientación en cuanto a sus derechos como familia, personas, así como también la visualización de posturas responsables o alternativas.

Con relación al desvelamiento del abuso sexual, la investiga muestra que 27 NNA, tienen miedo a represalias contra ellos mismos, contra sus padres y hermanos, 11 ignoran la prohibición y 5 tienen vergüenza, estos datos hacen presumir que pese a la información y promulgación de leyes de protección a NNA en situaciones de abuso sexual, no se dispone de conceptos claros de intervención, o se cree que la única manera de intervenir es desde la legislación, con grandes políticas, que por supuestos son útiles y necesarias, pero es preciso considera el contexto de la problemática también desde la individualidad y la colaboración ciudadana, la participación de redes informales, que la suma de varios actores para intervenir desde la prevención.

\section{Bibliografía:}

BARUDY, Jorge (1993), Dictaduras familiares: Maltrato infantil, Incesto, Terceras Jornadas Chilenas de Terapia Familiar, Santiago de Chile.

BARUDY, Jorge (1998), El dolor invisible de la infancia, Buenos Aires: Paidós.

BENAVIDES, Jacqueline (2004), Programa de autoprotección contra el abuso sexual infantil, Universidad de los Andes. Colombia.

CRIVILLÉ, Albert, y otros (1994), L'inceste. Comprender pour intervenir. Privat, Toulouse, (El incesto. Comprender para intervenir)

DUPRET, Marie-Astrid (2005), Delincuencia Juvenil, hacia una política de rehabilitación. Quito: Abya Yala. 
GARCES Paz, Hugo (2000), Investigación cientifica. Quito: Ediciones AbyaYala.

HÉRITIER, Francoise et al. (1994), Incesto. Buenos Aires: Ediciones Nueva Visión

NARANJO, Jorge

s/f El perfil de las usuarias adolescentes del HGDIA

TILMANS- OSTYN, Edith

s/f Nuevas tendencias en el tratamiento de maltrato y Abuso sexual en las familias.

RAVAZZOLA, María Cristina, (1997), Historias infames: los maltratos en las relaciones. Barcelona: Paidos.

CÓDIGO DE LA NIÑEZ Y ADOLESCENCIA 2003 FORO (1997), Reformas Constitucionales.

INNFA (s/f), Sistematización de las Conferencias del Equipo de San Diego y los Protocolos para la atención en Maltrato y Abuso Sexual Infantil y Adolescente.

(s/f) Segundo y Tercer Informes Oficiales consolidados de la aplicación sobre los derechos del niño en el Ecuador.

LA MAGIA DEL BUEN TRATO, Cartillas 8 Colección Manuelas

REDPAMN-Q (1998), Instrumento SIMI. 